\title{
LA FOTOGRAFÍA DE ANA ÁLVAREZ-ERRECALDE: EL RECICLAJE DE LAS FORMAS EN LA CONSTRUCCIÓN DE SENTIDO E IDENTIDAD
}

\author{
Maria Isabel Imbaquingo Pérez ${ }^{1}$ \\ Carlos Hugo Aulestia Páez ${ }^{2}$
}

\section{Introducción}

El debate que se plantea la fotografía desde las reflexiones sobre el campo del arte y el ámbito de la política constituyen una problemática epistemológica que enfrenta dos concepciones opuestas sobre la contaminación política en los fenómenos estéticos y la inocuidad del idealismo estético en la actividad artística como forma de comunicación y relación con los otros.

En este sentido, la obra de la artista visual Ana Álvarez-Errecalde (Argentina) constituye una expresión limítrofe en la que se materializa esta contraposición de la política frente al valor estético. En este ensayo se analizan dos propuestas fotográficas que ilustran la confusión y el disenso que se muestran tanto como la motivación cuanto como el sentido de este tipo de trabajos, y que condicionan la forma en que son asumidos y procesados por la sensibilidad de los receptores.

Ana Álvarez-Errecalde es una artista visual contemporánea cuya obra emplea diversos lenguajes como la fotografía, el audiovisual y el performance. Los temas de su trabajo artístico se ubican en ámbitos considerados anticanónicos, debido a su particular concepción del cuerpo y de los afectos humanos. Su obra explora los ciclos vitales y propone visiones del cuerpo y de lo humano desterradas de las lecturas y representaciones de la estética canónica: el parto, la crianza, el amamantamiento, la enfermedad, el envejeci-

\footnotetext{
${ }^{1}$ Pontificia Universidad Católica del Ecuador, Ecuador. Email: miimbaquingo@puce.edu.ec ORCID id: https://orcid.org/0000-0002-3492-7096

${ }^{2}$ Pontificia Universidad Católica del Ecuador, Ecuador. Email: chaulestia@puce.edu.ec ORCID id: https://orcid.org/0000-0002-8024-3912
} 
miento y la muerte. Sus etapas creativas más representativas están relacionadas con procesos vitales personales en los que resaltan especialmente lo corpóreo femenino, como 'Cesárea, más allá de la herida', 'Histologías', 'El nacimiento de mi hija', 'Mamá', 'Leche de madre', 'Duelo', 'Care, cuidar importa'. Su trabajo ha sido expuesto en Londres, Barcelona, Madrid y Buenos Aires. Su obra y su política sobre el arte se pueden revisar en su página personal: https://alvarezerrecalde.com/.

Las fotografías analizadas en esta propuesta se titulan 'Tres gracias sangrantes' y 'Anunciación', cuyo sentido es la visibilización y vindicación de los procesos sexuales y reproductivos de la mujer (en concreto la menstruación) y las dinámicas del cuidado de una maternidad conflictiva y ambivalente.

El objetivo de este análisis consiste en reflexionar sobre las estrategias de elaboración de la obra fotográfica que la autora argentina utiliza para desacreditar los presupuestos resguardados por la policía de la estética, en la construcción de subjetividades, a partir del pensamiento del conflicto entre estética y política tal como lo comprende Jacques Rancière, y la noción de reutilización de las formas y resignificación del sentido en el arte contemporáneo propuesta por Nicolas Bourriaud en su concepto de postproducción.

\section{Marco Teórico}

\subsection{Las políticas en la estética. El pensamiento de Rancière}

El problema de la estética, la política y la obra de arte es fundamental para comprender qué tipo de discurso es el que se propone en el trabajo de Ana Álvarez-Errecalde. Por una parte, los objetos de análisis seleccionados -las fotografías sobre una experiencia femenina concreta-, parecen obedecer a una intención específica, que consistiría en mostrar públicamente aquello que, dadas ciertas limitaciones que operan sobre este tipo de experiencias (consideradas o bien privadas o bien 'antiestéticas' y desagradables), debería permanecer oculto. Por otro lado, esta experiencia se representa desde los principios generales del quehacer artístico, pues está planteada como un performance fotográfico montado técnicamente y en directa alusión a obras plásticas consideradas canónicas. 
El conflicto que convierte a este tipo de expresiones en un problema estético y también en un asunto político tiene que ver con la forma en que históricamente se ha determinado qué entra en la esfera de lo artístico y que no, es decir, con lo que Jacques Rancière llama “el reparto de lo sensible" (2011a: 34). Los principios canónicos de la estética definen e imponen las reglas según las cuales entendemos qué es arte y qué no lo es. Esta definición se plantea a modo de un juicio, el juicio crítico, que se apoya en los principios teóricos del campo de la estética, cuyos debates internos están destinados, por sobre cualquier otro objetivo, a mantener el aparataje teórico que implica la administración y vigilancia de los presupuestos que rigen la manera de producir, exponer y comprender el trabajo artístico.

Así, para Rancière (2005), el régimen de comprensión de lo estético actúa en términos prácticos como una policía, es decir, como un agente de constricción que pretende mantener cierto orden establecido e invisibilizar las nuevas expresiones que no se sujetan a él.

Dado que el arte contemporáneo elabora representaciones de experiencias subjetivas, individuales y comunitarias, cuyo objetivo es la restitución de un sentido humano que ha sido desterrado del campo de la estética en favor de la dominación de la idea del arte absoluto y el artista como genio, muchas expresiones artísticas actuales buscan visibilizar aquello que, según los preceptos tradicionales resguardados por la policía de la estética, no debe ser exhibido, ni mostrado, ni, menos aún, disfrutado como arte. Así, existe la posibilidad de comprender un trabajo del tipo del que se analiza en este texto como una obra eludida por las regulaciones excluyentes de la estética tradicional, en virtud de un juicio crítico que lo podría catalogar como un discurso eminentemente político, y, por tanto, fuera de la circunscripción de lo artístico.

Ahora bien, para Rancière, la aparente oposición entre lo estético y lo político, que constituye el núcleo de su pensamiento filosófico, es en realidad una dinámica que se fundamenta precisamente en el disenso. Las obras contemporáneas generan, en la lógica de Rancière, un cuestionamiento de los discursos conservadores de la estética, cuyo objetivo histórico ha sido determinar los límites que definen lo que se considera artístico y cómo 
debe comprenderse, $\mathrm{y}$, por lo tanto, desterrar nuevas expresiones y nuevas sensibilidades del campo de lo estético.

En la misma línea de reflexión, la historiadora de arte colombiana Janneth Aldana Cedeño afirma que

El arte no solo cuestiona las formas predominantes a través de las cuales se recuerda y se determina lo que merece o no ser conmemorado, sino que a la vez se convierte en un importante espacio alternativo para grupos que no han sido incluidos en la historia "oficial", ya sea porque ellos no aportan en su escritura y elaboración general, o porque muchas veces son ignorados como sujetos participantes en ello. Es así como desde el arte, un arte más ligado con lo cotidiano que con la estrechez de las reglas artísticas académicas que han sido institucionalizadas, se reconfiguran recuerdos individuales y colectivos hacia nuevas preguntas sobre su propio desarrollo, para alejarse de construcciones particulares en la proyección de un futuro más cercano. (Aldana, 2010: 230)

Según Rancière, la política se opone a la policía, puesto que aquella está constituida como una actividad social que busca establecer, resignificar, reivindicar y visibilizar experiencias subjetivas que son inaceptables por los cánones y están sometidas a la vigilancia policial como una amenaza al orden instituido por el régimen que regula el campo de lo estético. La política es, de esta manera, todo esfuerzo por replantear los regímenes de comprensión del arte y generar un reparto de lo sensible distinto, equilibrado, equitativo y renovador.

El conflicto entre la política y la estética se produce como un encuentro entre dos lógicas, dos procesos discordantes, el de la policía, que impone las normas, y el de la política, que busca la igualdad. Son dos formas de reparto de lo sensible (Rancière, 2005). Rancière explica esta distribución de acuerdo con la definición de lugares, espacios y tiempos que delimitan la existencia de un campo común, lo que separa y excluye, por un lado, y lo que hace participar, por otro. La policía ejecuta y supervisa la distribución de nombres, lugares, espacios y funciones, naturaliza algunos, los legitima, y destruye así la igualdad (Rancière, 1996). Se determina de esta manera lo que es visible y lo que no puede serlo, quiénes tienen derecho a hablar y quiénes no, pues la policía es ante todo "un orden de los cuerpos que define las divisiones entre los modos de hacer, los modos de ser y los modos de decir" (Rancière, 1996: 44). 
Rancière recuerda que, en la estética del romanticismo, el juicio crítico aparece como 'desinteresado' o ajeno a la vida cotidiana, y que el arte “tal como Kant lo había fijado en su fórmula, era el lugar por excelencia de la negación de lo social” (2011a: 9).

El destierro que sufre el ámbito político del campo del arte aparece aquí como una condición para lograr el objetivo inmediato de la estética, que consiste en llegar a la sensibilidad del sujeto, conmoverlo, afectarlo emocionalmente con los instrumentos provistos por el genio (el geist) del artista y la naturaleza 'pura' de su obra. El vínculo generado entre el creador y el espectador está marcado por este idealismo absolutista. Así pues, quedan fuera de todo acto estético el hecho social, la toma de postura, el disenso, las relaciones de poder y la reivindicación de causas. En el mejor de los casos, para la estética, lo político se reduce al tema del que trata la obra, que es más o menos evidente en la forma en que el artista plantea su trabajo. En general, se considera que el vínculo entre ambos campos es posible en la obra artística a partir de una cierta cercanía tópica, que se manifiesta cuando el asunto de la obra es evidentemente político o cuando se puede percibir cierto grado de compromiso asumido por el autor con respecto a un conflicto social explícitamente expuesto.

La propuesta de Rancière es fundamental porque, desde el punto de vista opuesto, no circunscribe lo político al campo de la convivencia social. En realidad, para este autor, la política es un concepto ubicuo que se manifiesta en todas las esferas de lo humano. Tampoco se limita a un territorio o a acontecimientos contingentes. El objetivo de Rancière es eliminar la idea de que la política está presente en el arte solamente como un mensaje o una forma de transmisión de discursos de denuncia o reivindicación, puesto que existen diversas formas de conexión del arte con lo político.

Lo que define a la política, en oposición a la policía, es la capacidad de incorporar a aquellos sectores invisibles para el orden dominante, de manera que las fronteras conceptuales y pragmáticas establecidas desde ese orden dejen de operar y permitan la incorporación de nuevas expresiones y experiencias sensibles. La política de la estética debe comprenderse entonces como un nuevo reparto de la sensibilidad. 
Rancière reelabora conceptualmente la noción de política en oposición a ciertos planteamientos en los que identifica el perjuicio que se inflige a la "parte sin parte" (Ranciére, 1996: 7), es decir, a la comunidad de individuos cuyo sensorium ha sido excluido por la policía del régimen de comprensión de lo estético.

Lejos de demostrar la independencia de las actitudes estéticas respecto de las obras de arte, esto da prueba de un régimen estético donde se diluye la distinción entre las cosas que pertenecen al arte y aquellas que pertenecen a la vida ordinaria. (Rancière, 2011: 13-14).

Para el filósofo francés, la política aparece para producir una ruptura del orden de la dominación y provocar la redistribución de lo sensible, que consiste en afianzar otros modos de ver, decir, hacer, un nuevo ordenamiento de objetos y cuerpos, y la asignación replanteada de lugares y funciones en relación con un orden social (Rancière, 2002). Este ordenamiento es el territorio común de la estética y la política.

Por todo lo dicho, el arte puede ser considerado político en la medida en que, al igual que en la propia esfera política, redefine y modifica la comprensión de lo artístico desde una forma renovada de repartición de la sensibilidad, que genera nuevas formas de participación en la experiencia sensorial.

Este replanteamiento de las formas de comprensión de los mensajes artísticos, que implica la reconfiguración del reparto de la sensibilidad, abre un muy amplio abanico de posibilidades para la acción de la política contra la institucionalidad policial de los regímenes de comprensión del arte. De esta forma, en el arte contemporáneo, gracias al aparecimiento de nuevos soportes y formas de difusión de los mensajes, signados por la vigencia de las tecnologías, ha hecho visible un conjunto de trabajos políticos y estéticos que, efectivamente, subvierten los planteamientos de los regímenes de comprensión de lo artístico. Estas manifestaciones del arte contemporáneo comparten como escenario de enunciación, en la actualidad, espacios de interacción transversalizados por la digitalización y la circulación de las obras a un público masivo y heterogéneo.

\subsection{Los marcos de lectura del arte en la contemporaneidad, según Bourriaud}


La necesidad de tiempo y velocidad parece ser una de las características profundas de las sociedades contemporáneas, donde las 'autopistas de la comunicación' con sus kilómetros de datos y usuarios/consumidores masivos parecen ser los únicos lugares posibles de encuentro y de experiencia de los otros (Bourriaud, 2006). En medio de esta vorágine de información y de la conexión como símil de la relación, "la relación humana se ve obligada a tomar formas extremas o clandestinas" (p. 7) y el arte se plantea como una búsqueda y recuperación de las relaciones humanas y sus contextos sociales en el devenir de las formas.

El arte contemporáneo y sus formas de producción resultan "aparentemente inasibles" para los estándares del arte tradicional (Bourriaud, 2006: 5), de la modernidad, cuyos regímenes de valoración de la obra artística por medio de discursos críticos, perceptivas y aparatos canónicos, se habían concentrado en desterrar el sentido de lo humano de las prácticas artísticas en favor de la inmanencia de la obra. Por ejemplo, el caso de la crítica literaria tradicional que excluye al autor de la ficción narrativa o de la enunciación problemática y nunca se piensa que el autor esté incluido en la valoración de la obra. Así, la imposibilidad de comprender desde los estándares el arte contemporáneo radica en que este es escenario de prácticas sociales, humanas, y por lo tanto los modos de pensar el arte parten de la situación identitaria u ontológica de los artistas, de la relación, de su compromiso con la problematización de la fragilidad de las relaciones con el otro.

La posibilidad de un arte relacional -un arte que tomaría como horizonte teórico la esfera de las interacciones humanas y su contexto social, más que la afirmación de un espacio simbólico autónomo y privado- da cuenta de un cambio radical de los objetivos estéticos, culturales y políticos puestos en juego por el arte moderno. (Bourriaud, 2006: 13)

Así, el arte en la contemporaneidad, sus manifestaciones a través de la transformación y apropiación de las formas se presenta como el marco capaz de motivar las condiciones de relación y convertir la experiencia del arte en el escenario para los encuentros posibles. El arte contemporáneo propone entonces una abolición de la distancia entre el artista, la obra y el espectador. Así, como para Rancière (2010: 13), el teatro se presentaba como “el único lugar de confrontación del público consigo mismo como colectivo", la obra de arte contemporánea en su suerte de performance teatral y de conciencia de las prácticas y 
actos de la vida cotidiana, se propone como el lugar del nexo, de la relación, del encuentro comunitario.

Lo que nuestras performances verifican -ya se trate de enseñar o de actuar, de hablar, de escribir, de hacer arte o de verlo- no es nuestra participación en un poder encarnado en la comunidad. Es la capacidad de los anónimos, la capacidad que vuelve a cada uno/a igual a todo/a otro/a. Esta capacidad se ejerce a través de distancias irreductibles, se ejerce por un juego imprevisible de asociaciones y disociaciones. (p.22)

En la actualidad, muchos artistas construyen sus obras con el objetivo de hacer referencia, representar o visibilizar experiencias relacionadas con la dinámica social vigente marcada por problemáticas concretas y conflictos sociales asociados con la disolución de los vínculos relacionales que caracterizaban el entramado social. Así, por ejemplo, el "reciclaje de lo cultural", en términos de Bourriaud (2006), es una de las manifestaciones subversivas posibles del arte contemporáneo, donde la distinción y separación entre creación y copia, entre producción y consumo se desvanecen y proponen nuevos modos de apropiación de las formas (2007) y nuevas valoraciones del capital artístico, un “intersticio social" (2006: 13).

Este intersticio del que habla Bourriaud (2006) equivale o suplanta a la experiencia idealizada por el arte canónico según el cual la obra como forma pura era objeto de contemplación del observador en silencio. Tal es la pragmática del arte canónico. El intersticio en la multiplicidad de experiencias y formas de transmitir esos sentidos en el arte contemporáneo contradice la estética y la idealizada experiencia de la contemplación y la reemplaza por una vivencia relacional, que consiste en la actualización subjetiva del espectador que se apropia de la obra. En esta línea de pensamiento, el contacto particular e individual de cada observador renueva la reacción afectiva que produce el mensaje artístico.

Las ideas tradicionales sobre la obra artística como una forma independiente desprovista de cualquier conexión que no sea con la inspiración y el genio como un don divino, son derruidas en el arte contemporáneo por una nueva concepción de la creación artística, 
como un campo de contacto y reconocimiento de subjetividades. Estas identidades implican una colaboración relacional entre el artista como generador de una propuesta en la que ofrece una imagen de su propio yo, que está implicado en la obra, puesto que la ha creado, y el observador como receptor solidario en la construcción de esa imagen y, por lo tanto, como un agente activo en esta experiencia de reconstrucción del creador. De esta forma, el contacto idealizado por los cánones estéticos tradicionales, según los cuales la obra constituía una manifestación inasible para el observador pasivo, se convierte, en el arte contemporáneo, en una invitación a la exploración y reconocimiento del otro como una forma de generación de un vínculo social fundamentado en una experiencia comunicativa integral.

Esta experiencia comunicativa se materializa a partir de la inscripción de "la obra de arte en el interior de una red de signos y significaciones, en lugar de considerarla como una forma autónoma u original” (Bourriaud, 2007: 13). Así, el recurrir y reutilizar formas ya producidas plantea nuevos marcos tanto para el uso como para la interpretación y representación de las identidades y las subjetividades. “Aprender a servirse de las formas... es ante todo saber apropiárselas y habitarlas" (p.14). El nexo relacional se vuelve posible en la medida en que los códigos históricos y culturales son retomados y reprogramados en una suerte de proceso generador de vínculos infinitos en razón de sus múltiples posibilidades de apropiación, caracterizadas por la "difuminación de las fronteras entre consumo y producción” (p.16), por la continuidad en el relato y por la transformación del estatuto de la obra de arte que, "al convertirse en generadora de comportamientos y de potenciales reutilizaciones..., vendría a contradecir la cultura 'pasiva' que opone las mercancías y sus consumidores" (p.17).

En el arte contemporáneo la obra no solo es posible en tanto creación colectiva, sino que su valor radica en sus usos y en la reutilización de sus formas, a lo que Bourriaud (2007) concibe como el 'comunismo de las formas'.

Todos los elementos, tomados de cualquier parte, pueden ser objetos de nuevos abordajes. [...] Todo puede servir. Es obvio que no solamente podemos corregir una obra o integrar diferentes fragmentos de obras permitidas dentro de una nueva, sino también cambiar el sentido de esos fragmentos y alterar de todas las maneras que se consideren buenas. (Debord en Bourriaud, 2007: 40) 


\section{Discusión}

\subsection{La elaboración de un mensaje estético-político en la obra de Ana Álvarez-Erre- calde}

Como se planteó al inicio de este texto, la contraposición que enfrentan los campos de la experiencia estética y el discurso político han generado un espacio de construcción de expresiones estéticas que a la vez constituyen manifestaciones políticas. En este territorio, lo político debe entenderse como un campo en el que se configuran las subjetividades, las experiencias personales y las prácticas y los objetos cotidianos como formas significantes y por tanto estéticas. Así, la obra de Ana Álvarez-Errecalde se presenta de entrada como una propuesta transgresiva y renovadora; en este sentido, política, en términos de Rancière. La motivación creativa de esta autora radica en su voluntad de romper con los marcos de representación establecidos sobre el cuerpo como un objeto estético que se presenta no en forma de unidad, sino de divergencia y multiplicidad y, por tanto, como el lugar de identidades particulares y únicas.

El análisis que se plantea en este artículo responde a la necesidad de desautomatizar sentidos e interpretaciones legitimadas y validadas por posturas tradicionalistas en el arte que han impuesto una visión idealizada del cuerpo y sus procesos orgánicos como entidad viva. En este sentido, el gesto transgresivo de la obra de la artista Álvarez-Errecalde implica, además de su propio valor estético, una disrupción que pone en cuestión estos principios.

Las ideas de Jacques Rancière sobre el régimen del arte explican satisfactoriamente el sentido y la importancia de la renovación de los fundamentos de la obra de arte considerando su dimensión política, que responde al disenso y al cuestionamiento que se lleva a efecto a través de la resignificación crítica de las regulaciones canónicas, como ocurre en el caso de las fotografías de análisis. En la misma línea, Nicolas Bourriaud plantea la necesidad de la apropiación del sentido de lo artístico para generar nuevas formas de 
creación y recepción. Así pues, las fotografías seleccionadas corresponden al plantemiento de Bourriaud de referenciar una obra como una forma de posproducirla para dotarla de un nuevo sentido y marco de interpretación.

El trabajo de la imagen sobre la diversidad de los cuerpos genera posibilidades de representación estética que chocan con los cánones y regímenes de representación del cuerpo en la estética tradicional. Para Álvarez Errecalde, el cuerpo se plantea como lugar de resistencia, cuya estrategia es la exposición del cuerpo 'sin velo', es decir, la piel, los órganos, la sangre mostrados explícitamente para desestabilizar o cuestionar la repartición simbólica de la sensibilidad, que distingue lo público de lo privado y descarta la visibilización de la organicidad interna del cuerpo.

Las fotografías de la artista se han concebido como correlativas a obras de arte clásicas, reconocidas como obras maestras en los regímenes de comprensión de lo estético hegemónico. En este sentido, la propuesta de la artista argentina constituye una suerte de hipertexto o continuidad del relato respecto de dos obras consagradas en el ámbito de las artes plásticas, lo cual implica tanto una resignificación en el ámbito semántico como un reciclaje de las formas en la puesta en escena, en el montaje.

En la figura 1, se muestra el conjunto de imágenes 'Tres gracias sangrantes', compuesto por tres performance fotográficos que autorretratan a la artista menstruando en diferentes poses del cuerpo en relación con la sangre. La obra que la artista 'reprograma', en términos de Bourriaud, para posibilitar la continuidad del relato, es las 'Tres gracias', de Antonio Canova ${ }^{3}$, que corresponde a una representación escultórica de las tres Cárites de la mitología griega: Aglaya, belleza; Eufrósine, júbilo y Thalía, abundancia.

El conjunto fotográfico de Ana Álvarez-Errecalde difiere de la obra de Canova en que presentan a un solo sujeto -la artista- en distintas posturas corporales, mientras que la escultura de las 'Tres Gracias' constituye una unidad compuesta por tres representaciones

\footnotetext{
${ }^{3}$ Antonio Canova (1757-1822), pintor y escultor italiano. Es considerado uno de los mayores representantes del neoclasicismo y el mejor escultor italiano después de Bernini, de quien muestra influencia en su trabajo. Entre sus principales obras, destacan Orfeo y Eurídice; Dédalo e Ícaro; Venus y Marte, Amor y Psique y Las tres gracias.
} 
distintas. Las Cárites, en tanto diosas, hijas de Zeus, pertenecen a un orden ontológico divino y simbolizan virtudes modélicas o dones otorgados por los dioses a los seres humanos. En el trabajo de Álvarez-Errecalde, el halo divino ha sido reemplazado por la sangre menstrual, que adquiere así un valor simbólico equiparable a la dádiva celestial que plantea el mito clásico.

La transgresión de esta serie de imágenes consiste sobre todo en el hecho de que la sangre menstrual no ha sido contenida ni ocultada y brota del cuerpo natural y espontáneamente hacia la superficie. Esta representación de la experiencia de la menstruación cuestiona la práctica culturalmente establecida de interrumpir el flujo menstrual y ocultarlo por medio de productos comerciales que coaccionan a las mujeres a invisibilizar los procesos naturales del cuerpo femenino. La sangre se presenta como un don, no provisto por los dioses sino por la propia naturaleza femenina, manifestada en los procesos de la corporalidad. Se trata de una ruptura del régimen de reconocimiento de lo estético, y, por lo tanto, de una propuesta política, en términos de Rancière, puesto que no existe en el arte canónico una representación de la menstruación. De existir esta representación, sería planteada de manera metafórica, figurativa, mediante la utilización de lenguaje retórico para evitar exhibir de forma explícita el flujo menstrual. Pero, ¿cuál es la intención de mostrar en la fotografía la menstruación como una forma de transgredir las regulaciones de la estética?

En primer lugar, la sangre menstrual es un signo manifiesto de la madurez sexual de la mujer y remite, por tanto, a su fertilidad. Ambos fenómenos, la sexualidad y la fertilidad, han sido controlados y tutelados por regímenes patriarcales que, en sus construcciones narrativas de los procesos sexuales y reproductivos de la mujer, han relacionado la sexualidad con la idea del mal, el pecado y la impureza. Esta atribución de sentido que opera sobre el fenómeno menstrual posibilita la configuración de una codificación legitimada 
de la representación de lo femenino vinculada con la idea de la virginidad como virtud y la maternidad incorpórea y pura encarnada en la imagen de la Virgen María.
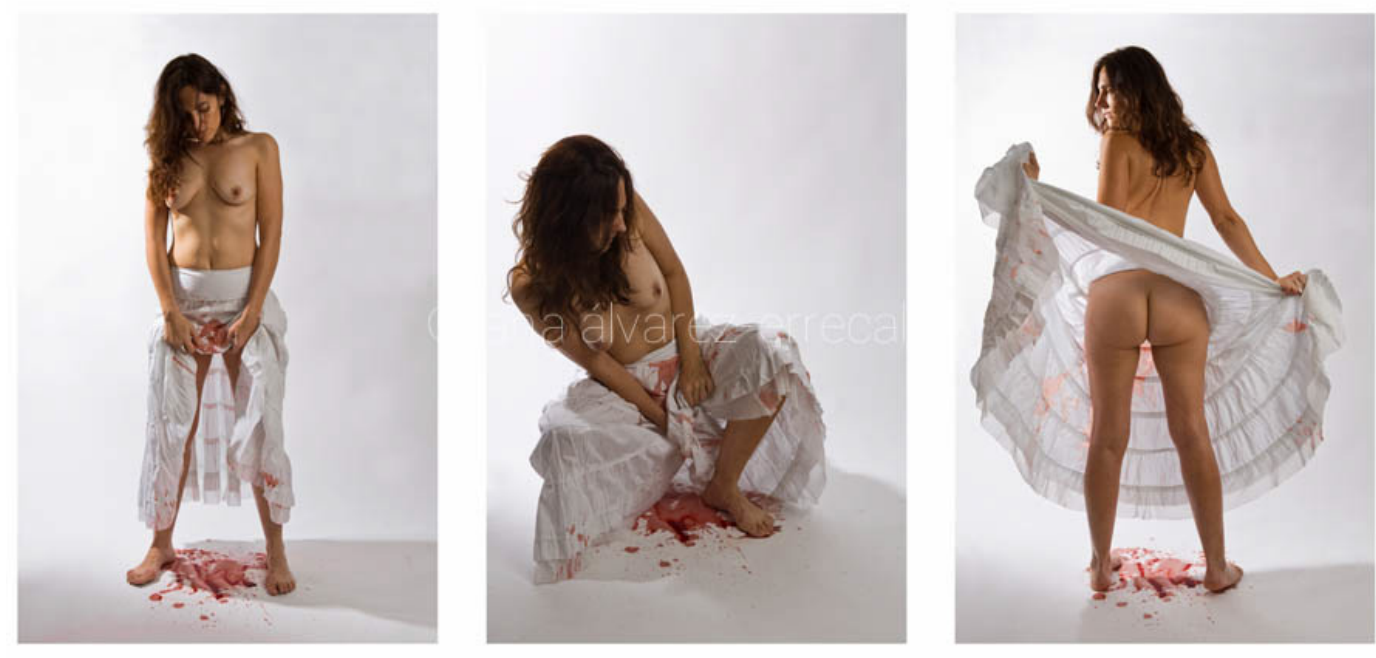

Figura 1. Tres Gracias Sangrantes C)Ana Álvarez-Errecalde (2012)

En la figura 2, se aprecia el autorretrato fotográfico de la artista sentada y sosteniendo en su regazo a su hijo adolescente, quien nació con una malformación cerebral congénita y yace en los brazos de su madre como si fuera un cuerpo inerte. La fotografía se titula 'Anunciación' y forma parte de una muestra llamada 'Las cuatro estaciones' (20132014), que retratan las experiencias maternas de la artista. En esta fotografía se destaca el juego transtextual con la célebre 'Pietà' de Miguel Ángel. Al igual que la fotografía anterior, en 'Anunciación' existe un proceso de transgresión y de resignificación del régimen estético, que además resulta más complejo si atendemos al título de la obra. La anunciación es un motivo pictórico tratado por varios autores (Fra Angélico, Botticelli, Leonardo), que reproduce la visita del Arcángel Miguel para anunciar a María que será madre del hijo de Dios. Así pues, la fotografía de Ana Álvarez-Errecalde constituye una alusión a las formas y al sentido de dos obras canónicas que tienen que ver con la experiencia de la maternidad.

En la 'Pietà' de Miguel Ángel vemos el sufrimiento de María una vez que se ha consumado el destino de su hijo, y por lo tanto su propio sino como madre. Este consiste en la 
predeterminación de su vida por orden divina en función del sacrificio, el sufrimiento y la agonía de su hijo, todo lo cual constituye un correlato de su propio padecimiento como madre. La imagen de Álvarez-Errecalde plantea en términos similares su propia experiencia maternal marcada por el sacrificio y el dolor de ser madre de una criatura incapaz de valerse por sí misma, al borde de la muerte, sin libertad y sin voluntad, como Cristo. De esta forma, la maternidad de María y la de la artista se vinculan por el sacrificio, el dolor y el amor incondicional. No obstante, la diferencia substancial entre estas dos experiencias maternas consiste en la esencia profundamente humana de la experiencia de la artista, que se manifiesta en la fotografía mediante signos de lo cotidiano como la toalla en el pelo, la bata de baño y el espacio doméstico.

En ambos casos, el de María y el de la artista, sus destinos como madres se anticipan en el acontecimiento fundamental de la anunciación, que en el caso de la Virgen María proviene de lo divino y comunica la determinación de criar un hijo para la muerte, y en la experiencia de Ana Álvarez-Errecalde se expresa mediante la sentencia médica.

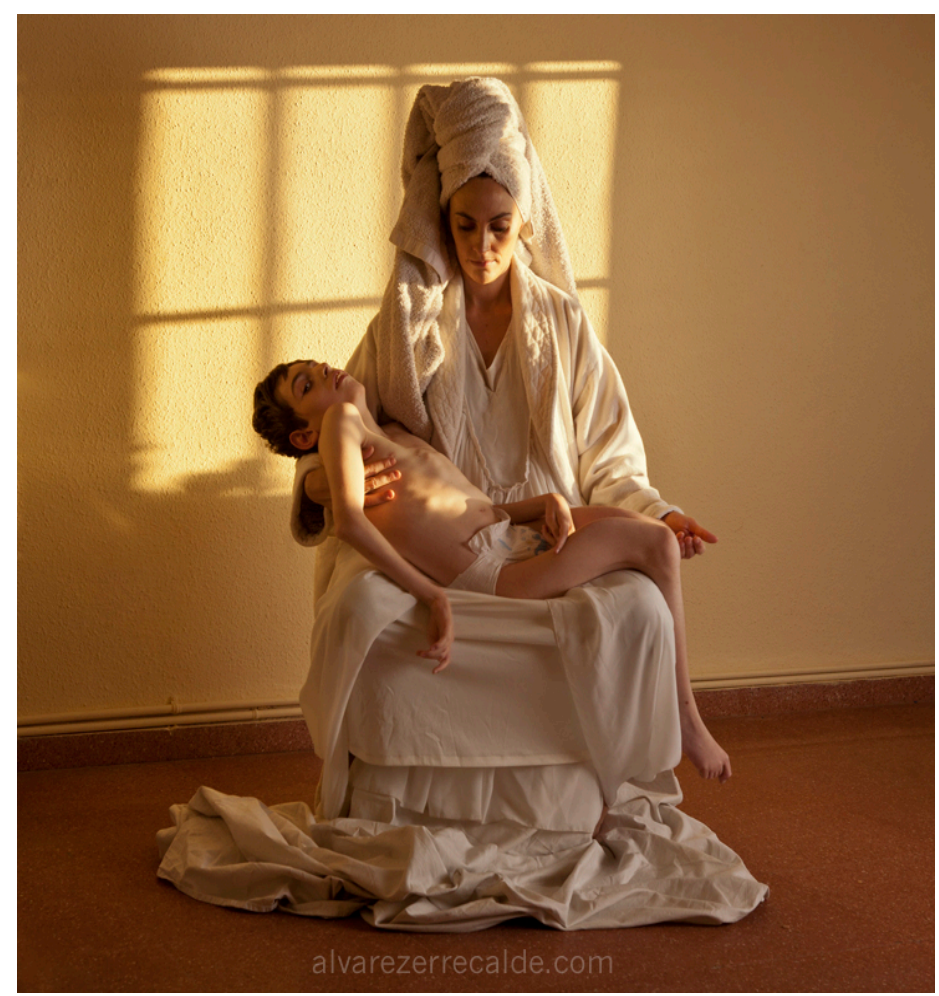

Figura 2. "Anunciación” - Serie Las cuatro estaciones (C)Ana Álvarez-Errecalde (2014) 
En las fotografías, la artista reutiliza los signos para enfatizar el sentido de su propia obra, en contraste con los significados asignados canónicamente a obras clásicas, para generar una contraposición en la que el plano de lo humano es tanto o más significativo que las representaciones de la influencia de lo divino en la trascendencia de las representaciones de lo femenino. La artista realiza un performance, monta una escena de la obra clásica, $y$ es en ese performar donde, en palabras de Rancière, la artista se transforma en espectadora activa y devuelve a la obra su virtud original de conocimiento en la acción.

La fotografía como construcción de la subjetividad y de la identidad de la artista se propone como un acto de emancipación, que para Rancière significa "la alteración de la frontera entre los que actúan y los que miran, entre individuos y miembros de un cuerpo colectivo." (2010: 24). Para que esta emancipación se pueda producir, existe previamente otro fenómeno relevante relacionado con la naturaleza transgresiva de la fotografía en su dimensión política, el cual consiste en incluir a la propia artista y su experiencia vital como el núcleo mismo de la obra. Esta estrategia genera una forma renovada de relación con los receptores (puesto que no se la toma como una construcción ficticia), sino como el resultado de una experiencia humana cargada de una intensidad afectiva y emocional que pertenece al mismo registro sensible del observador.

Esto quiere decir que, mediante las estrategias que pone en funcionamiento Ana ÁlvarezErrecalde, queda abolida en su obra la distancia insalvable, planteada desde los cánones de la estética, entre el artista y el público. Además, reconoce y cuestiona la maternidad como no lugar, cuya construcción social y sus múltiples representaciones discursivas, políticas, artísticas, entre otras, han sido expresadas sin identidad, sin relación, vacías (Vadillo, 2009), como representaciones carentes de narración propia y contradictorias con respecto a la experiencia materna, pero fieles a la maternidad como institución (Rich, 1986).

De la misma forma, el tratamiento de lo íntimo como una estrategia de construcción del concepto mismo de autor, que en los principios del arte canónico se presenta como un genio inalcanzable, es renovado y replanteado en esta propuesta fotográfica, puesto que 
la autoría como posesión de la obra está diluida y se presenta como una acción performativa que pone en contacto representaciones clásicas con una experiencia subjetiva concreta en la cual lo íntimo invisibilizado se expresa y se exhibe ante la comunidad.

De esta manera, el trabajo fotográfico de Ana Álvarez-Errecalde es una muestra de la redistribución de lo sensible que opera en el arte contemporáneo y de la política que, siguiendo a Rancière, interviene como una propuesta renovada de comprender las formas de relación y producción de sentido que generan nuevas maneras de plantear lo sensible.

Asimismo, los mensajes estéticos de la obra fotográfica muestran su espíritu político en la intención de proveer un marco de lectura que radica en la construcción de una identidad colectiva sobre los procesos sexuales y reproductivos de la mujer y la visibilización de los cuidados. Ana Álvarez-Errecalde construye una poética en la que los cuerpos se visualizan sin ninguna idealización estética, en toda la crudeza de su naturalidad corpórea. Para la artista, el cuerpo no es un modelo idealizado del ser humano; es el propio ser en su vulnerabilidad y fragilidad que constituyen elementos condicionantes de su existencia. Por ejemplo, además de los recursos expuestos en el conjunto fotográfico analizado, en varias de sus propuestas artísticas podemos reconocer los elementos visuales que conforman su poética, como la sangre y los órganos expuestos en 'Nacimiento de mi hija', la piel en 'Histologías', la herida en 'Cesárea', la vejez, la enfermedad y la muerte en 'Vida' y 'Care, cuidar importa 'y el dolor, en 'Duelo'. Mediante estos recursos, la artista descubre y descubre la naturaleza del cuerpo oculta por la estetización artificial que opera en las representaciones de lo orgánico humano en la estética tradicional.

\section{Conclusiones}

La obra fotográfica de Ana Álvarez-Errecalde se comprende como una expresión política, en el sentido de Rancière. Las fotografías objeto de este análisis contienen elementos que en el régimen de comprensión de lo estético dominante serían objetadas o desacreditadas por la policía que regula este campo. Tanto la menstruación como la experiencia maternal conflictiva del cuidado de un hijo al borde de la vida constituyen temas considerados íntimos, personales y particulares. Por esta razón, el régimen estético niega su valor como 
obra inmanente, puesto que responden a la experiencia terrenal y a las emociones individuales, y no a las cualidades formales de la obra ni al repertorio de tópicos codificables como arte.

La estética canónica constituye, en las manifestaciones políticas del arte, una referencia funcional para facilitar la producción y la difusión del mensaje a colectivos invisibilizados como receptores del arte clásico. En el caso de las fotografías examinadas se comprueba que existe una operación transtextual que consiste en deconstruir las obras clásicas y utilizar sus componentes, bien técnicos o bien simbólicos, para componer un nuevo mensaje que, siendo esencialmente político, adopta la lógica de la representación artística, cuyo objetivo es la conmoción de la sensibilidad, para proponer nuevos marcos de interpretación en un orden distinto al régimen de comprensión de lo estético.

En términos de Bourriaud, la artista reutiliza las formas de las obras clásicas como una estrategia de continuidad del relato, para enfatizar el sentido de la experiencia subjetiva de la obra. De esta manera, la autora, a través de estas fotografías, propone un recorrido propio de los signos y sentidos de las obras clásicas a la vez que les otorga una nueva significación.

El tipo de manifestación artística en el que se inscribe el trabajo fotográfico de la artista pretende equiparar los temas particulares y las vivencias individuales como formas de exhibir lo humano y reconfigurar las relaciones y fronteras entre el productor de mensajes artísticos y los consumidores de esos mensajes. En este sentido, propone la horizontalidad de la práctica artística que involucra una igualdad de derechos para la artista y el observador, cuyas funciones como tales se encuentran cuestionadas bajo la lógica de que las formas artísticas constituyen una continuidad de relatos, y adicionalmente activa la empatía en favor de la generación de un reparto comunitario de la sensibilidad. 


\section{REFERENCIAS}

ALDANA, Janneth. (2010) Arte y política. Entre propaganda y resistencia. Anuario Colombiano de Historia Social y de la Cultura, Bogotá, vol. 37, n. 2, pág. 221-243, BOURRIAUD, Nicolas. Estética relacional. Buenos Aires, Adriana Hidalgo Editora, 2006

BOURRIAUD, Nicolas. Postproducción. Buenos Aires, Adriana Hidalgo Editora, 2007 RANCIÈRE, Jacques. El desacuerdo. Filosofía y Política. Buenos Aires, Nueva Visión, 2007

RANCIÈRE, Jacques. La división de lo sensible. Estética y Política. Salamanca, Consorcio Salamanca, 2002

RANCIÈRE, Jacques. Sobre politicas estéticas. Barcelona, Museu d'Art Contemporani de Barcelona, 2005

RANCIÈRE, Jacques. El espectador emancipado. Buenos Aires, Manantial, 2010

RANCIÈRE, Jacques. El malestar de la estética, Buenos Aires, Capital Intelectual, 2011 RICH, Adrienne. Nacemos de mujer: la maternidad como experiencia y como institución. Valencia, Cátedra, 1986

VADILLO, Marisa. La deconstrucción del cuerpo femenino: el "no-lugar" en el arte. En I ${ }^{0}$ Congreso Universitario Andaluz "Investigación y Género", 2009, Sevilla. Libro de actas. Sevilla: Universidad de Sevilla, 2009, pp. 1385-1402.

Disponible en: https://dialnet.unirioja.es/servlet/articulo?codigo=4949521

Recebido: 22/03/2021

Aprovado: 02/06/2021 